\title{
Verification of the methodology for evaluating tumor-infiltrating Iymphocytes in colorectal cancer
}

\author{
Shinji Matsutani ${ }^{1}$, Masatsune Shibutani $^{1}$, Kiyoshi Maeda $^{1}$, Hisashi Nagahara $^{1}$, \\ Tatsunari Fukuoka ${ }^{1}$, Yasuhito Iseki ${ }^{1}$, Kosei Hirakawa ${ }^{1}$ and Masaichi Ohira ${ }^{1}$ \\ ${ }^{1}$ Department of Surgical Oncology, Osaka City University Graduate School of Medicine, Osaka, Japan \\ Correspondence to: Masatsune Shibutani, email: fbxbj429@ybb.ne.jp \\ Keywords: tumor-infiltrating lymphocytes; TILs; prognostic marker; colorectal cancer; methodology \\ Received: May 23, 2017 Accepted: February 21, 2018 Epub: March 08, 2018 Published: March 16, 2018 \\ Copyright: Matsutani et al. This is an open-access article distributed under the terms of the Creative Commons Attribution License \\ 3.0 (CC BY 3.0), which permits unrestricted use, distribution, and reproduction in any medium, provided the original author and \\ source are credited.
}

\section{ABSTRACT}

Background: The density of tumor-infiltrating lymphocytes (TILs) have been reported to reflect antitumor immune response and correlate with prognosis in malignancy. However, the methodology for evaluating the density of TILs by an immunohistochemical analysis differs among reports. The aim of this study was to verify the methodology for evaluating the density of TILs by immunohistochemical analysis and thereby identify the optimum methodology in clinical setting.

Methods: Three-hundred-thirteen patients who underwent curative operation for stage II/III colorectal cancer were enrolled. We retrospectively examined the density of TILs using immunohistochemical staining according to each method as follows: 1) subset of lymphocytes (i.e. $\mathrm{CD4}^{+} / \mathrm{CD8}^{+}$), 2 ) selected fields (i.e. at random or focusing on hot spots), 3) location in low-power field (i.e. the invasive margin [TILs ${ }^{\mathrm{IM}}$ ] or the center of the tumor [TILs $\left.{ }^{\mathrm{CT}}\right]$ or the surface of the tumor [TILs $\left.{ }^{\mathrm{ST}}\right]$ ), and 4) location in high-power field (i.e. in tumor stroma [sTILs] or intra-tumor cells [iTILs] or total TILs [tTILs: sTILs+iTILs]). We then assessed the prognostic value of the density of TILs ${ }^{\mathrm{IM}}$ evaluated as described above. We also evaluated the correlation between the density of TILs ${ }^{\mathrm{IM}}$ and that of TILs ${ }^{\mathrm{CT}} /$ TILs $^{\mathrm{ST}}$.

Results: Only the densities of $\mathrm{CDB}^{+}{ }^{+} \mathrm{TILs}^{\mathrm{IM}}$ and $\mathrm{CDB}^{+}{ }^{+} \mathrm{TILs}^{\mathrm{IM}}$ evaluated in randomly selected fields were significantly associated with the survival. Furthermore, the density of $\mathrm{CDB}^{+}{ }^{+} \mathrm{TLS}^{\mathrm{IM}}$ was significantly associated with that of $\mathrm{CDB}^{+}$TILs $^{\mathrm{CT}}$ and CD8 ${ }^{+}$TILs ${ }^{\text {ST }}$.

Conclusions: We concluded that best and easiest way to evaluate the density of TILs in the clinical setting may be to assess the density of $\mathrm{CD8}^{+}{ }^{+}$TILs $^{\mathrm{IM}}$ in randomly selected fields.

\section{INTRODUCTION}

Colorectal cancer (CRC) is the third-most common cancer worldwide, with a cumulative lifetime risk of approximately $5 \%[1,2]$, and the clinical outcome of $\mathrm{CRC}$ is poor, as one-third of patients who undergo curative resection die within 5 years after surgery [3]. To identify patients at high risk of disease recurrence, AJCC/UICCtumor-node-metastasis (TNM) classification is employed most frequently as a prognostic classification. However, the prognostic value of this system is limited [4]. Therefore, genetic and molecular tumor prognostic factors have alternatively been proposed to identify patients who may be at risk for recurrence. However, none of these have been sufficiently informative for inclusion in clinical practice [5]. The identification of patients at high risk of disease recurrence therefore remains a major clinical issue.

As the primary host immune response against malignant tumors, tumor-infiltrating lymphocytes (TILs) have been reported to have a crucial effect on tumor 
progression and the clinical outcome in various types of cancer, including non-small cell lung cancer (NSCLC), colorectal, esophageal, and urothelial cancers and melanoma [6-13]. Furthermore, Galon et al. [14] reported that the density of TILs are more valuable prognostic markers than the TNM classification. However, while a number of methods have been proposed for evaluating the density of TILs, none has yet been confirmed to be optimum.

Some researchers have evaluated the density of TILs in Hematoxylin-Eosin-stained sections, and others have evaluated the density of the subset of TILs in immunohistochemical-stained sections. The methodology for evaluating the density of TILs by immunohistochemical staining differs among reports, with suggested methods as follows: selected fields (i.e. at random or focusing on hot spots), location in high-power field (i.e. in tumor stroma, intra-tumor cells, and total TILs), and location in low-power field (i.e. the invasive margin, the center of the tumor, surface of the tumor). As described above, no standard methodology for evaluating the density of TILs has yet been established. Therefore, a standardized methodology for evaluating the density of TILs is required in order to apply this biomarker in the clinical setting.

The aim of this study was to identify the optimum methodology for evaluating the density of TILs by immunohistochemical staining to help predict the prognosis of patients.

\section{RESULTS}

\section{Patients' characteristics in the exploratory study}

The patient characteristics are listed in Table 1 . The resected specimens were pathologically classified according to the seventh edition of the UICC TNM classification of malignant tumors. The distribution of cancer stages was as follows: stage II, 72; stage III, 67 patients. Mismatch repair status was as follows: proficient, 133; deficient, seven patients. All patients were followed up regularly with physical and blood examinations, including measurements of the levels of tumor markers, such as carcinoembryonic antigen (CEA) and carbohydrate antigen 19-9 (CA19-9), and mandatory screening using colonoscopy and computed tomography until August 2016 or death. The median follow-up period for the survivors in this study was 64.0 months (range: 6-107). Seventeen patients died during the follow-up period due to CRC.

\section{A survival analysis for TILs ${ }^{\mathrm{IM}}$ in randomly selected field in the exploratory study}

We assessed the prognostic value of the density of TILs at the invasive margin, in which the characteristics of the tumor have been recognized to be most accurately reflected [15]. The densities of CD4 ${ }^{+}$tTILs $^{\mathrm{IM}}$, sTILs ${ }^{\mathrm{IM}}$, and iTILs $^{\mathrm{IM}}$ showed no prognostic significance (Figure 1A, 1B, 1C). However, high-CD8 ${ }^{+}$tTILs $^{\mathrm{IM}}$ and sTILs $^{\mathrm{IM}}$ were significantly associated with high disease-specific survival (DSS) rates $(p=0.037, p=0.030$, respectively) (Figure $1 \mathrm{D}, 1 \mathrm{E})$, although the density of $\mathrm{CD}^{+}{ }^{+} \mathrm{TILs}^{\mathrm{IM}}$ was not associated with the prognosis (Figure 1F).

\section{A survival analysis for TILs ${ }^{\mathrm{IM}}$ in hot spots in the exploratory study}

In our evaluation focusing on hot spots, the densities of all TILs evaluated by each method showed no prognostic significance (Figure 2).

\section{Correlations between the density of $\mathrm{CD8}^{+} \mathrm{tTILs}^{\mathrm{IM}}$ and the clinicopathological factors in the exploratory study}

The density of $\mathrm{CD}^{+} \mathrm{tTILs}^{\mathrm{IM}}$ in randomly selected field exhibited no significant relationship with any of the clinicopathological parameters, except for lymph node metastasis $(\mathrm{p}=0.028)$ (Table 2$)$.

\section{Correlations between the MMR status and the density of $\mathrm{CD8}^{+} \mathrm{tTILs}^{\mathrm{IM}}$ in the exploratory study}

The density of $\mathrm{CD}^{+} \mathrm{tTILs}^{\mathrm{IM}}$ in randomly selected fields in MMR-D patients tended to be higher than that in MMR-P patients $(p=0.077)$ (Figure 3A).

\section{Prognostic factors influencing the survival in the exploratory study}

The correlations between the DSS and various clinicopathological factors are shown in Table 3. A multivariate analysis indicated that none of the factors were independent prognostic factors for the DSS.

\section{Correlation between the density of TILs ${ }^{\mathrm{IM}}$ and TILs $^{\mathrm{CT}} / \mathrm{TILs}^{\mathrm{ST}}$ in the exploratory study}

The densities of $\mathrm{CD}^{+}$tTILs $^{\mathrm{CT}}$ and $\mathrm{CD}^{+} \mathrm{tTILs}^{\mathrm{ST}}$ were significantly associated with that of $\mathrm{CD}^{+} \mathrm{tTILs}^{\mathrm{IM}}$ in randomly selected fields (TILs ${ }^{\mathrm{CT}}$ (Figure 4A): $\mathrm{r}=0.71$, $\mathrm{p}<0.001 ;$ TILs $^{\mathrm{ST}}$ (Figure 4B): $\mathrm{r}=0.57, \mathrm{p}<0.001$ ).

\section{Patients' characteristics in the validation study}

The patient characteristics are listed in Table 1 . The distribution of cancer stages was as follows: stage II, 96 patients; stage III, 78 patients. All patients were followed up as described above until September 2017 or death. The median follow-up period for the survivors in this study was 62.1 months (range: 13-89). Eighteen patients died during the follow-up period due to CRC. 
Gender

Male

Female

Age (years)

Median (range)

Location of primary tumor

Colon

Rectum

Tumor depth*

T1-3

T4

Tumor diameter $(\mathrm{cm})$

Median (range)

Histological type

Well, Moderately

Poorly, Mucinous

Lymphatic involvement

Negative

Positive

Venous involvement

Negative

Positive

Lymph node metastases

Negative

Positive

Mismatch repair status

Proficient

Deficient
$65(29-89)$

72

67

70

69

92

47

$5.0(1.0-11.0)$

133

6
89

85

$69(21-96)$

102

72

117

57

$4.0(0.8-12.0)$

162

12

54

120

134

40

96

78

164

10

*: According to UICC.TNM Classification of Malignant Tumors (seventh edition).

\section{A survival analysis for TILs ${ }^{\mathrm{IM}}$ in randomly selected fields in the validation study}

We assessed the prognostic value of the density of TILs at the invasive margin. High-CD $8^{+}$tTILs $^{\text {IM }} /$ sTILs $^{\text {IM }}$ were significantly associated with high DSS rates, just as in the exploratory study (both $\mathrm{p}<0.001$ ) (Figure 5D, 5E). In addition, high-CD8 ${ }^{+}$iTILs $^{\mathrm{IM}}$ tended to be associated with high DSS rates $(p=0.069)$ (Figure 5F).

\section{A survival analysis for TILs ${ }^{\mathrm{IM}}$ in hot spots in the validation study}

In the evaluation focusing on hot spots, the densities of all TILs evaluated by each method showed no prognostic significance, just as in the exploratory study (Figure 6).
Correlations between the density of $\mathrm{CD8}^{+}$tTILs $^{\mathrm{IM}}$ and the clinicopathological factors in the validation study

The density of $\mathrm{CD}^{+} \mathrm{tTILs}^{\mathrm{IM}}$ in randomly selected fields exhibited no significant relationship with any of the clinicopathological parameters (Table 2).

\section{Correlations between the MMR status and the density of $\mathrm{CD8}^{+} \mathrm{tTILs}^{\mathrm{IM}}$ in the validation study}

The density of $\mathrm{CD}^{+} \mathrm{tTILs}^{\mathrm{IM}}$ in randomly selected fields in MMR-D patients was significantly higher than that in MMR-P patients $(\mathrm{p}=0.012)$ (Figure 3B). 


\section{Prognostic factors influencing the survival in the validation study}

The correlations between the DSS and various clinicopathological factors are shown in Table 4. A multivariate analysis indicated that lymph node metastasis (hazard ratio, 4.30; 95\% confidence interval, 1.26-20.03; $\mathrm{p}=0.019)$ and the density of CD $8^{+} \mathrm{tTILs}^{\mathrm{IM}}$ in randomly selected fields (hazard ratio, 14.94; 95\% confidence interval, 4.65-60.02; $\mathrm{p}<0.001)$ was an independent prognostic factor for the DSS.

\section{Correlations between the density of TILs ${ }^{\mathrm{IM}}$ and TILs $^{\mathrm{CT}} / \mathrm{TILs}^{\mathrm{ST}}$ in the validation study}

The densities of $\mathrm{CD} 8^{+}$tTILs $^{\mathrm{CT}}$ and $\mathrm{CD} 8^{+}$tTILs $^{\mathrm{ST}}$ were significantly associated with that of CD $8^{+} \mathrm{tTILs}^{\mathrm{IM}}$ in randomly selected fields, just as in the exploratory study

\section{At random}
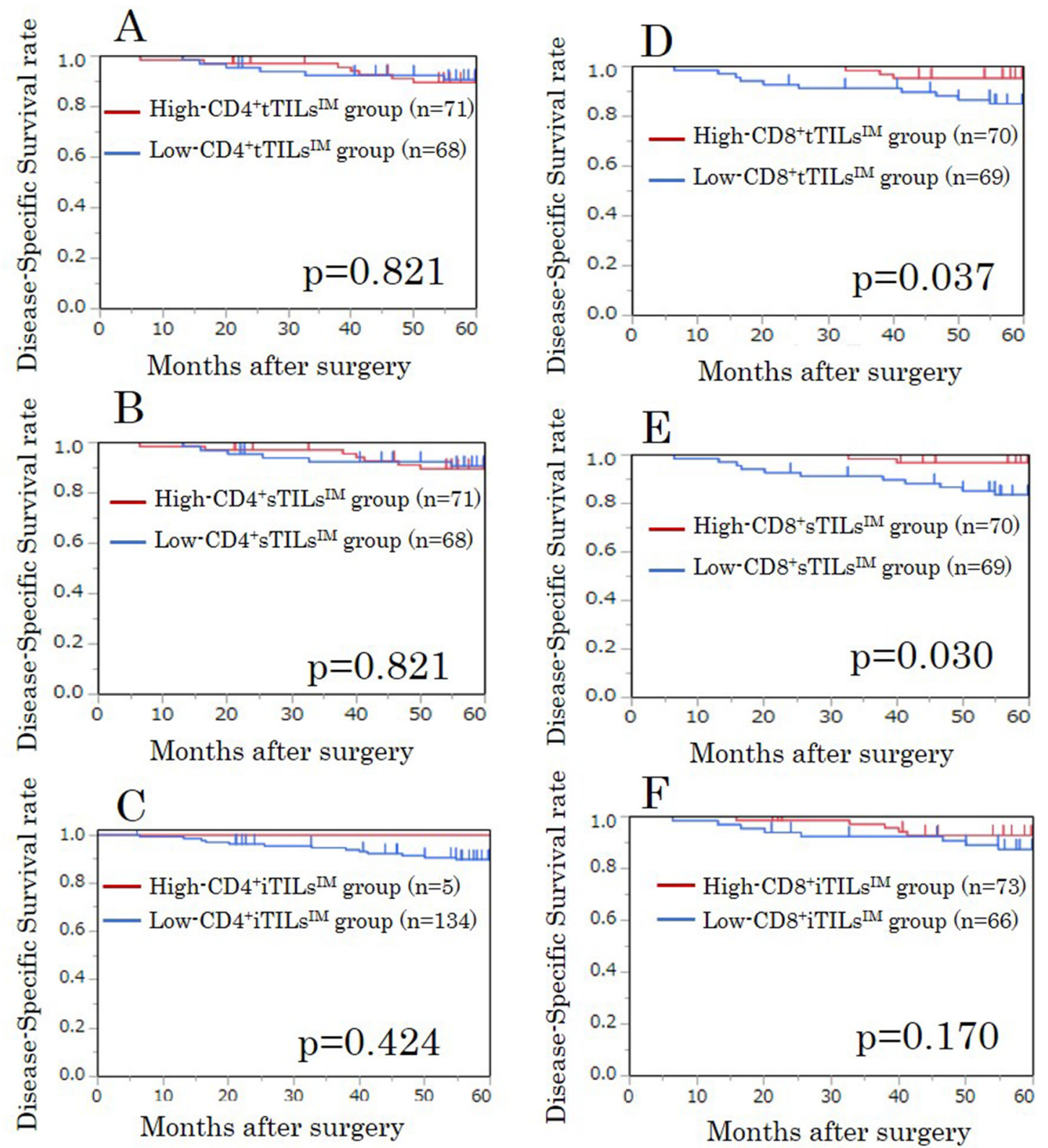

Figure 1: Kaplan-Meier survival curves for the disease-specific survival according to the density of CD4/CD8 ${ }^{+}$TILs at the invasive margin (TILs ${ }^{\mathrm{IM}}$ ) in randomly selected fields in the exploratory study. (A) CD4 $4^{+}$tTILs $^{\mathrm{IM}}$. (B) CD $^{+}$sTILs $^{\mathrm{IM}}$. (C) $\mathrm{CD}^{+}{ }^{+}$iTILs $^{\mathrm{IM}}$. (D) $\mathrm{CD}^{+}$tTILs $^{\mathrm{IM}}$. (E) $\mathrm{CD}^{+}$sTILs $^{\mathrm{IM}}$. (F) $\mathrm{CD} 8^{+}$iTILs $^{\mathrm{IM}}$. tTILs, total TILs. sTILs, TILs in tumor stroma. iTILs, TILs intra-tumor cells. 
(TILs $^{\mathrm{CT}}$ (Figure 7A): $\mathrm{r}=0.70, \mathrm{p}<0.001 ;$ TILs $^{\mathrm{ST}}$ (Figure 7B): $\mathrm{r}=0.61, \mathrm{p}<0.001)$.

\section{DISCUSSION}

The current study showed that the densities of both total $\mathrm{CD}^{+}$TILs and CD8 ${ }^{+}$TILs in tumor stroma at the invasive margin were associated with the prognosis in patients with Stage II/III CRC. While many previous reports have found the density of TILs as evaluated by immunohistochemical staining to be a useful prognostic marker, the methodology for evaluating the density of TILs has not been standardized. To our knowledge, this is the first report to describe the detailed methodology for evaluating the density of TILs by immunohistochemical staining.

\section{Hot spot}
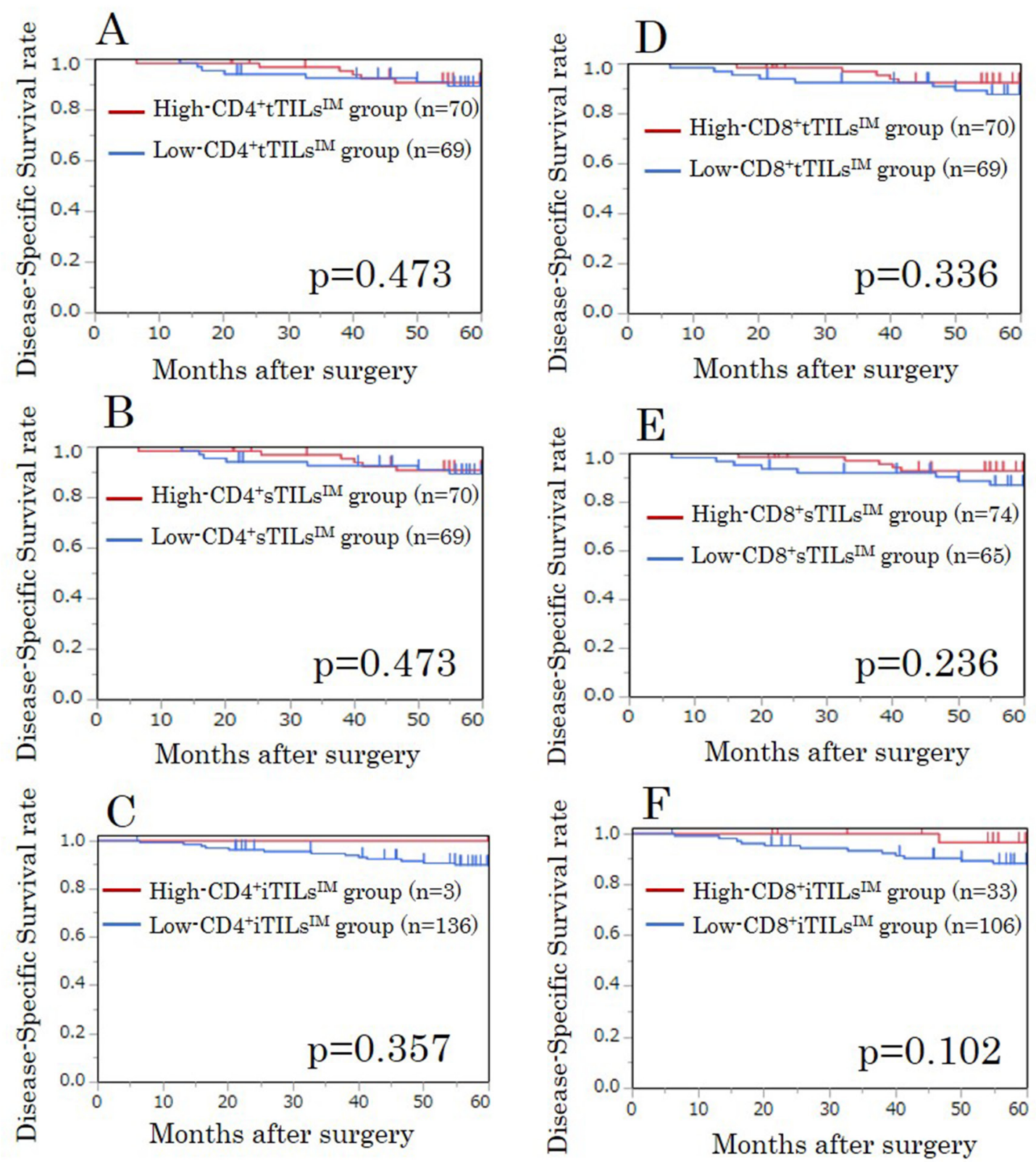

Figure 2: Kaplan-Meier survival curves for the disease-specific survival according to the density of CD4/CD8 ${ }^{+} \mathrm{TILs}$ at the invasive margin (TILs ${ }^{\mathrm{IM}}$ ) focusing on hot spots in the exploratory study. (A) CD $4^{+} \mathrm{tTILs}^{\mathrm{IM}}$. (B) $\mathrm{CD}^{+}{ }^{+} \mathrm{sTILs} \mathrm{s}^{\mathrm{IM}}$. (C) $\mathrm{CD}^{+}{ }^{+} \mathrm{TILs}^{\mathrm{IM}}$. (D) $\mathrm{CD}^{+} \mathrm{tTILs}^{\mathrm{IM}}$. (E) $\mathrm{CD}^{+}$sTILs $^{\mathrm{IM}}$. (F) $\mathrm{CD}^{+}$iTILs $^{\mathrm{IM}}$. tTILs, total TILs. sTILs, TILs in tumor stroma. iTILs, TILs intra-tumor cells. 
Table 2: Correlations between the density of $\mathrm{CD8}^{+} \mathrm{tTILs}^{\mathrm{IM}}$ and the clinicopathological factors

\begin{tabular}{|c|c|c|c|c|c|c|}
\hline & \multicolumn{3}{|c|}{$\begin{array}{c}\text { Exploratory Group } \\
\text { CD8+tTILs }\end{array}$} & \multicolumn{3}{|c|}{$\begin{array}{c}\text { Validation Group } \\
\text { CD8+tTILs }\end{array}$} \\
\hline & Low & High & p-value & Low & High & p-value \\
\hline \multicolumn{7}{|l|}{ Gender } \\
\hline Male & 33 & 39 & & 23 & 66 & \\
\hline Female & 36 & 31 & 0.398 & 13 & 72 & 0.095 \\
\hline \multicolumn{7}{|l|}{ Age (years) } \\
\hline$<65$ & 35 & 30 & & 14 & 47 & \\
\hline$\geq 65$ & 34 & 40 & 0.397 & 22 & 91 & 0.695 \\
\hline \multicolumn{7}{|l|}{ Tumor depth* } \\
\hline $\mathrm{T} 1-3$ & 41 & 51 & & 26 & 91 & \\
\hline $\mathrm{T} 4$ & 28 & 19 & 0.109 & 10 & 47 & 0.553 \\
\hline \multicolumn{7}{|l|}{ Tumor diameter $(\mathrm{cm})$} \\
\hline$<5$ & 33 & 32 & & 21 & 80 & \\
\hline$\geq 5$ & 36 & 38 & 0.866 & 15 & 58 & 1.000 \\
\hline \multicolumn{7}{|l|}{ Tumor location } \\
\hline Right side & 19 & 14 & & 11 & 47 & \\
\hline Left side & 50 & 56 & 0.325 & 25 & 91 & 0.843 \\
\hline \multicolumn{7}{|l|}{ Histological type } \\
\hline Well, Moderate & 64 & 63 & & 32 & 130 & \\
\hline Poorly, Mucinous & 5 & 7 & 0.764 & 4 & 8 & 0.274 \\
\hline \multicolumn{7}{|c|}{ Lymphatic involvement } \\
\hline Negative & 12 & 18 & & 9 & 45 & \\
\hline Positive & 57 & 52 & 0.303 & 27 & 93 & 0.425 \\
\hline \multicolumn{7}{|l|}{ Venous involvement } \\
\hline Negative & 53 & 60 & & 25 & 109 & \\
\hline Positive & 16 & 10 & 0.198 & 11 & 29 & 0.267 \\
\hline \multicolumn{7}{|c|}{ Lymph node metastasis } \\
\hline Negative & 29 & 43 & & 19 & 77 & \\
\hline Positive & 40 & 27 & 0.028 & 17 & 61 & 0.851 \\
\hline \multicolumn{7}{|l|}{$\mathrm{CEA}(\mathrm{ng} / \mathrm{ml})$} \\
\hline$<5$ & 39 & 48 & & 22 & 80 & \\
\hline$\geq 5$ & 30 & 22 & 0.163 & 14 & 56 & 0.851 \\
\hline \multicolumn{7}{|l|}{ CA19-9 (U/ml) } \\
\hline$<37$ & 58 & 65 & & 32 & 123 & \\
\hline$\geq 37$ & 8 & 5 & 0.389 & 3 & 12 & 1.000 \\
\hline
\end{tabular}

*: According to UICC.TNM Classification of Malignant Tumors (seventh edition).

CEA, carcinoembryonic antigen; CA19-9, carbohydrate antigen 19-9. 
The current study demonstrated that the density of CD4 ${ }^{+}$TILs may not be useful as a prognostic marker, while the density of CD8 ${ }^{+}$TILs may be useful as a prognostic marker for malignancy. Although some authors have reported that $\mathrm{CD} 4^{+}$TILs may be a prognostic predictor for malignancies $[16,17]$, we concluded that the density of CD4 ${ }^{+}$TILs was not associated with the prognosis because $\mathrm{CD}^{+} \mathrm{T}$ cells can be classified into more detailed subsets, such as T helper 1 (Th1) cells, Th2 cells, Th17 cells, and regulatory $\mathrm{T}$ (Treg) cells, and the functions of each $\mathrm{CD}^{+}$ $\mathrm{T}$ cell subset differ with regard to antitumor immunity. For example, Th1 cells produce cytokines, such as interferon- $\gamma$ (INF- $\gamma$ ), which activate $\mathrm{CD} 8^{+} \mathrm{T}$ cells [7]. Therefore, Th1 cells have been reported to enhance the antitumor immune response [18]. However, Th2 cells seem to suppress the antitumor immune response via the activation of $\mathrm{B}$ cells or the production of the immunosuppressive cytokine IL-10 [7]. In addition, findings regarding the function of Th17 cells in antitumor immunity have been controversial. For example, some authors have reported that Th17 cells facilitate the antitumor immune response, while other authors have reported that Th17 cells accelerate tumor growth via neoangiogenesis of the tumor [7]. Treg cells have been reported to suppress the antitumor immune response [7]. In contrast, $\mathrm{CD}^{+} \mathrm{T}$ cells (cytotoxic $\mathrm{T}$ lymphocytes) have been reported to have direct cytotoxic effects on tumor cells via the antitumor immune response and also be strongly associated with prolonged survival [7, 10, 19]. Recently, Galon et al. developed the "immunoscore" as a prognostic indicator using the density of $\mathrm{CD}^{+} \mathrm{TILs}$ and reported that this score might better reflect the prognosis of cancer patients than the TNM classification $[6,8]$.

In the current study, the average density of CD8 ${ }^{+}$TILs evaluated in five different randomly selected fields was a strong prognostic biomarker. We considered it important to evaluate the antitumor immune status of the whole tumor by evaluating the density of TILs in multiple fields selected randomly in order to resolve the issue of the heterogeneity of the density of TILs in the tumor [20]. However, many previous reports have not described the methodology used to select the fields in which the density of TILs was evaluated $[15,21]$. The absence of a consistent methodology for selecting fields may prevent us from accurately evaluating the antitumor immune status. The current study showed that the number of CD8 ${ }^{+}$TILs evaluated by focusing on hot spots was not associated with the survival, although a previous report in a large cohort showed that the number of $\mathrm{CD}^{+}$TILs evaluated in areas containing hot spots was significantly associated with the survival [10]. We considered that the number of $\mathrm{CD}^{+} \mathrm{TILs}$ evaluated in large areas containing hot spots using an image analyzer well-reflected the average density of TILs (i.e. the antitumor immune status in the whole tumor) [10]. In contrast, the number of CD8 ${ }^{+}$TILs evaluated by focusing on hot spots may not reflect the antitumor

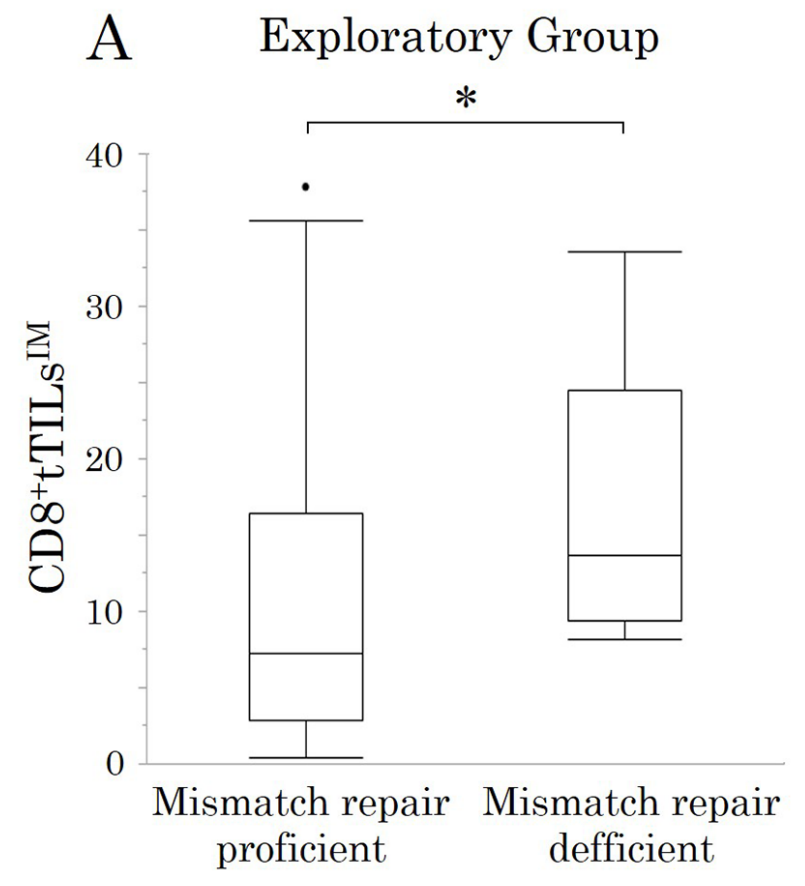

\section{B Validation Group}

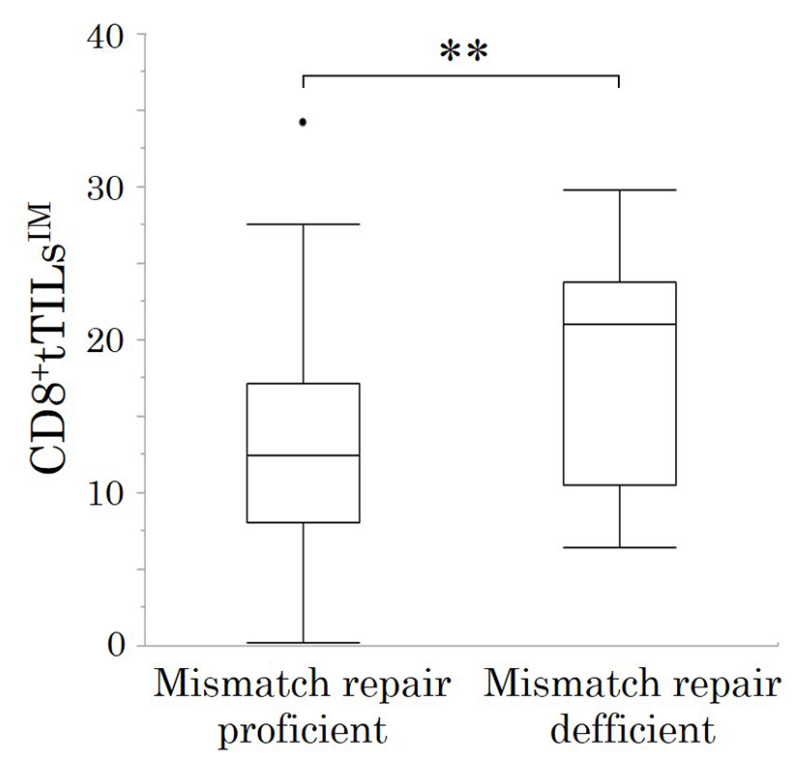

Figure 3: The correlations between mismatch repair status and the density of total CD8 ${ }^{+}$TILs at the invasive margin $\left(\right.$ CD8 $^{+}$tTILs $\left.^{\mathrm{IM}}\right)$ in randomly selected fields. ${ }^{*} \mathrm{p}<0.1,{ }^{* *} \mathrm{p}<0.05$. 
Table 3: Correlations between the disease-specific survival and various clinicopathological factors in the exploratory study

\begin{tabular}{|c|c|c|c|c|c|c|}
\hline & \multicolumn{3}{|c|}{ Univariate analysis } & \multicolumn{3}{|c|}{ Multivariate analysis } \\
\hline & HR & $95 \% \mathrm{CI}$ & p-value & HR & $95 \% \mathrm{CI}$ & p-value \\
\hline Age $(\geq 65$ vs. $<65)$ & 2.078 & $0.754-6.602$ & 0.161 & 1.485 & $0.498-4.926$ & 0.482 \\
\hline Tumor depth (T4 vs. T1-3) & 2.067 & $0.760-5.625$ & 0.151 & 0.920 & $0.283-3.001$ & 0.889 \\
\hline $\begin{array}{l}\text { Histological type (Poorly, Mucinous vs. } \\
\text { Well, Moderately) }\end{array}$ & 2.327 & $0.533-7.228$ & 0.229 & 1.283 & $0.226-6.049$ & 0.764 \\
\hline $\begin{array}{l}\text { Lymphatic involvement (Positive vs. } \\
\text { Negative) }\end{array}$ & 4.522 & $0.915-81.764$ & 0.068 & 1.589 & $0.264-30.523$ & 0.656 \\
\hline $\begin{array}{l}\text { Venous involvement (Positive vs. } \\
\text { Negative) }\end{array}$ & 3.042 & $1.034-8.206$ & 0.044 & 2.550 & $0.795-7.630$ & 0.111 \\
\hline $\begin{array}{l}\text { Lymph node metastasis (Positive vs. } \\
\text { Negative) }\end{array}$ & 5.244 & $1.705-22.791$ & 0.003 & 2.247 & $0.625-10.771$ & 0.225 \\
\hline CEA $(\geq 5 \mathrm{ng} / \mathrm{ml}$ vs. $<5 \mathrm{ng} / \mathrm{ml})$ & 5.905 & $2.086-20.987$ & $<0.001$ & 2.922 & $0.881-11.308$ & 0.080 \\
\hline CA19-9 ( $\geq 37 \mathrm{U} / \mathrm{ml}$ vs. $<37 \mathrm{U} / \mathrm{ml})$ & 6.348 & $1.968-17.975$ & 0.004 & 2.730 & $0.598-10.723$ & 0.184 \\
\hline $\begin{array}{l}\text { The density of CD } 8^{+} \mathrm{tTILs}^{\mathrm{IM}} \text { in randomly } \\
\text { selected field (Low vs. High) }\end{array}$ & 3.135 & $1.092-11.216$ & 0.033 & 1.886 & $0.567-7.424$ & 0.308 \\
\hline $\begin{array}{l}\text { Mismatch repair status (deficient vs. } \\
\text { proficient) }\end{array}$ & $<0.001$ & NA & 0.223 & $<0.001$ & $0.000-33.366$ & $>0.999$ \\
\hline
\end{tabular}

HR, hazard ratio; CI, confidence interval; CEA, carcinoembryonic antigen; CA19-9, carbohydrate antigen 19-9; tTILs ${ }^{\mathrm{IM}}$, total tumor-infiltrating lymphocytes at the invasive margin; NA, not available.

immune status in the whole tumor, because observers evaluated the density of $\mathrm{CD} 8^{+}$TILs in extremely small areas (i.e. high-power fields) in the current study. We may therefore have incorrectly categorized some patients with low lymphocyte infiltration as having high lymphocyte infiltration. The density of CD8 $8^{+}$TILs should be evaluated not in the fields focusing on hot spots but in those selected randomly when performing observer-based evaluations.

We found that the density of CD8 ${ }^{+}$TILs intra-tumor cells was not a useful prognostic biomarker, despite
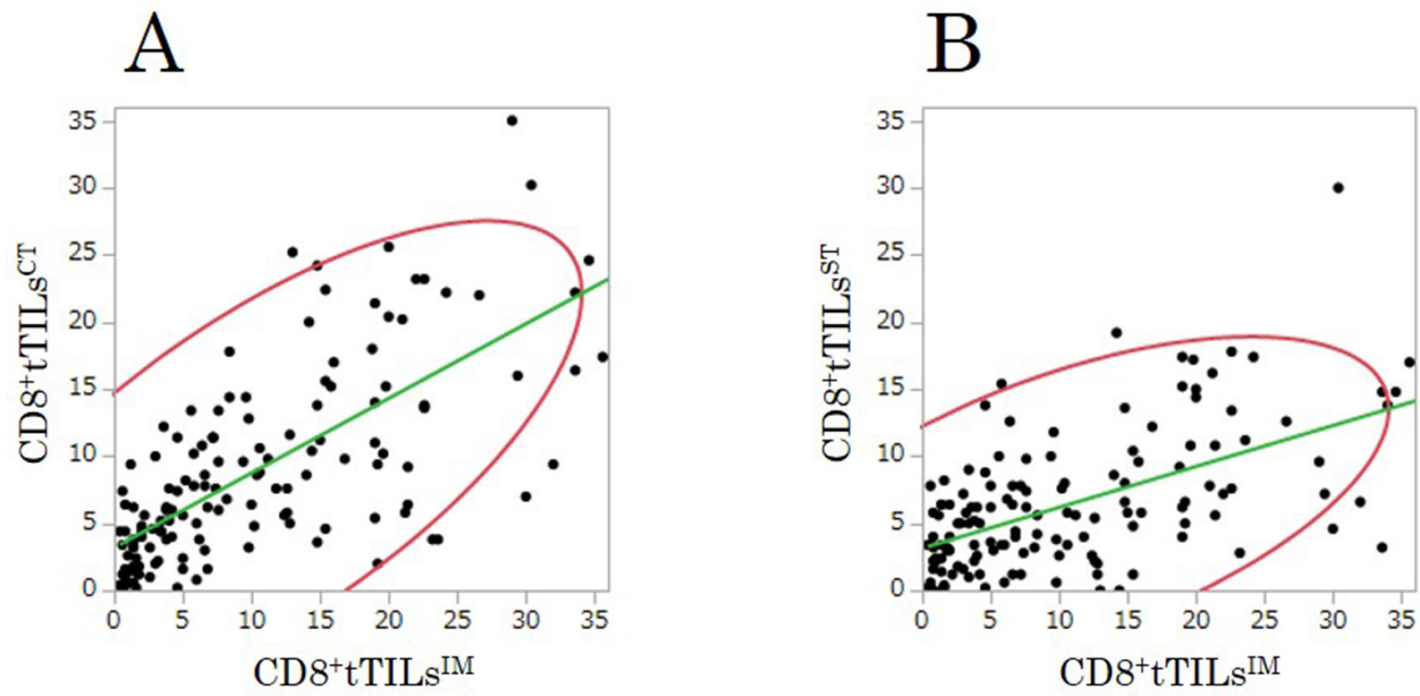

Figure 4: The correlations between the densities of total $\mathrm{CD8}^{+}{ }^{\mathrm{TILs}}$ at the center of the tumor $\left(\mathrm{CDB}^{+} \mathrm{tTILs}^{\mathrm{CT}}\right) / \mathrm{at}^{\text {the }}$ surface of the tumor $\left(\mathrm{CD8}^{+} \mathrm{tTILs}^{\mathrm{ST}}\right)$ and that of total $\mathrm{CD8}^{+} \mathrm{TILs}$ at the invasive margin $\left(\mathrm{CD8}^{+} \mathrm{tTILs}^{\mathrm{IM}}\right)$ in randomly selected fields in the exploratory study. (A) center: $r=0.705$, $p<0.001$. (B) surface: $r=0.568, p<0.001$. 
previous reports on the prognostic utility of the density of $\mathrm{CD}^{+}$TILs intra-tumor cells $[22,23]$. The density of CD8 ${ }^{+}$TILs intra-tumor cells may be unlikely to reflect differences in the antitumor immune status among patients sensitively, as the absolute number of CD8 $8^{+}$TILs intratumor cells evaluated in high-power fields was quite low. CD8 ${ }^{+}$TILs intra-tumor cells, which showed a markedly low density in our study, may not be a useful prognostic biomarker in the clinical setting, although CD8 ${ }^{+}$TILs intratumor cells may have biological significance.

We found that evaluating the density of total CD8 ${ }^{+}$TILs without distinguishing between TILs in tumor stroma and TILs intra-tumor cells was an ideal and easyto-perform method in the clinical setting. Previous studies in large cohorts $[10,21]$ have shown that a high density of total CD8 ${ }^{+}$TILs was associated with a good survival.

At random
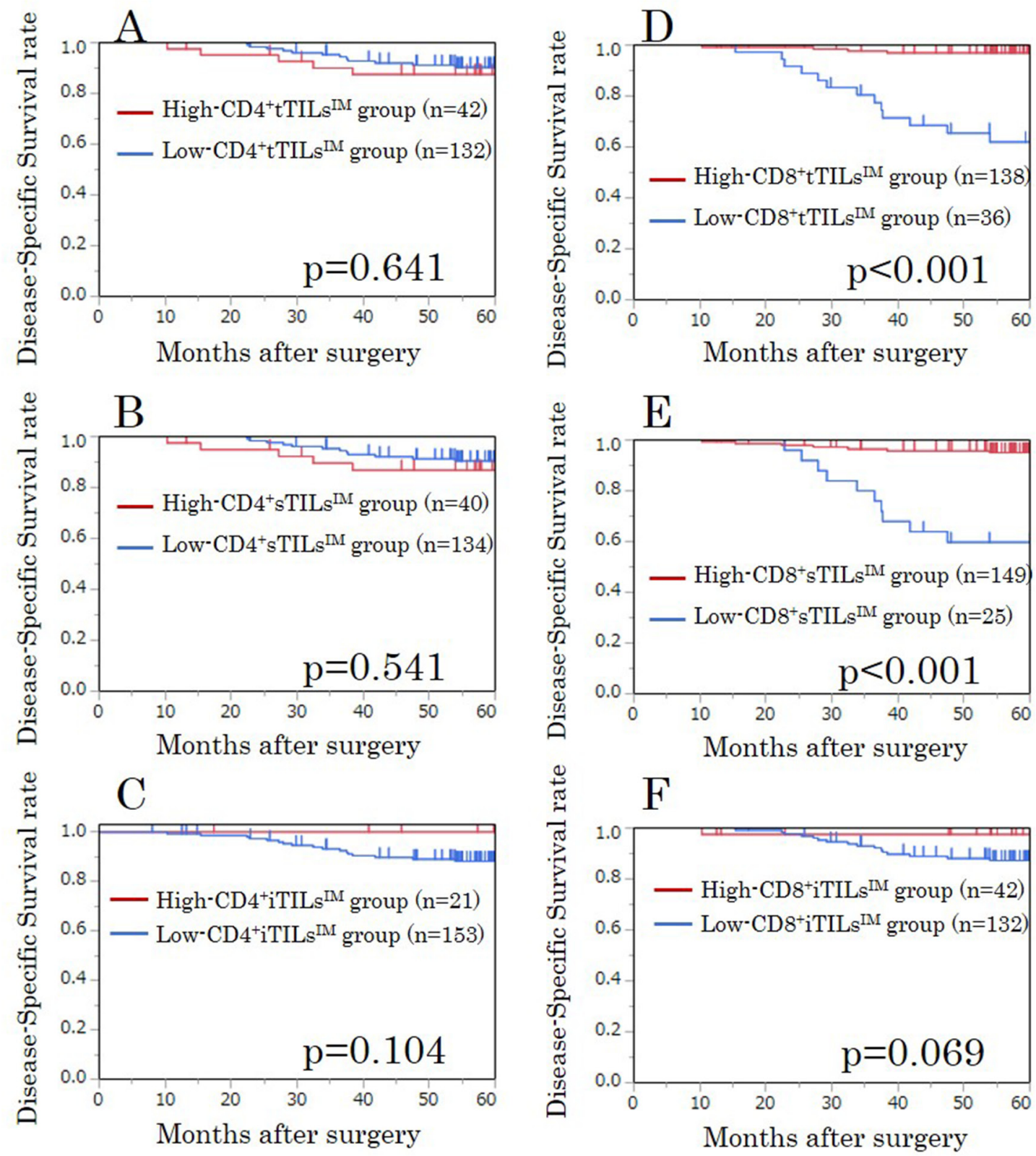

Figure 5: Kaplan-Meier survival curves for the disease-specific survival according to the density of CD4/CD8 ${ }^{+}$TILs at the invasive margin (TILs ${ }^{\mathrm{IM}}$ ) in randomly selected fields in the validation study. (A) CD4 $4^{+} \mathrm{tTILs}^{\mathrm{IM}}$. (B) $\mathrm{CD}^{+} \mathrm{sTILs}^{\mathrm{IM}}$. (C) $\mathrm{CD}^{+}$iTILs $^{\mathrm{IM}}$. (D) $\mathrm{CD}^{+}$tTILs $^{\mathrm{IM}}$. (E) $\mathrm{CD}^{+}$sTILs $^{\mathrm{IM}}$. (F) $\mathrm{CD}^{+}$iTILs $^{\mathrm{IM}}$. tTILs, total TILs. sTILs, TILs in tumor stroma. iTILs, TILs intratumor cells. 
Furthermore, the prognostic indicator "immunoscore" [24] described above included the evaluation of the density of total CD8 ${ }^{+}$TILs. In our results, the number of total TILs was similar to that of TILs in tumor stroma, as the number of TILs intra-tumor cells was extremely low. We therefore considered that the evaluation of the density of total TILs was more reasonable than the evaluation of that of TILs in tumor stroma in analyses performed using an image analyzer [10, 15, 25], which has difficulty distinguishing between TILs intra-tumor cells and TILs in tumor stroma. Furthermore, the evaluation of total TILs without distinguishing between TILs intra-tumor cells and TILs in tumor stroma was a useful and easyto-perform method for evaluations carried out by an observer.
High-grade MSI (MSI-H) CRC is reportedly more immunogenic with greater infiltration by immune cells than microsatellite stable (MSS) CRC because of the large number of tumor antigens produced by frameshift mutations $[26,27]$. Patients with MSI-H Stage II/III CRC have been found to have a better prognosis than those with MSS CRC [28], because MSI-H tumors are suppressed by a strong antitumor immune response associated with MSI-H tumors. Based on these findings, the MSI status may induce a bias in the association between the density of TILs and the prognosis. Although MMR-D tumors had greater $\mathrm{CD} 8^{+}$TIL infiltration than MMR-P tumors in the current study, relatively few CRC patients had MMR-D tumors $(5.1 \%)$, and the density of $\mathrm{CD}^{+}$TILs was an MMR status-independent prognostic biomarker.

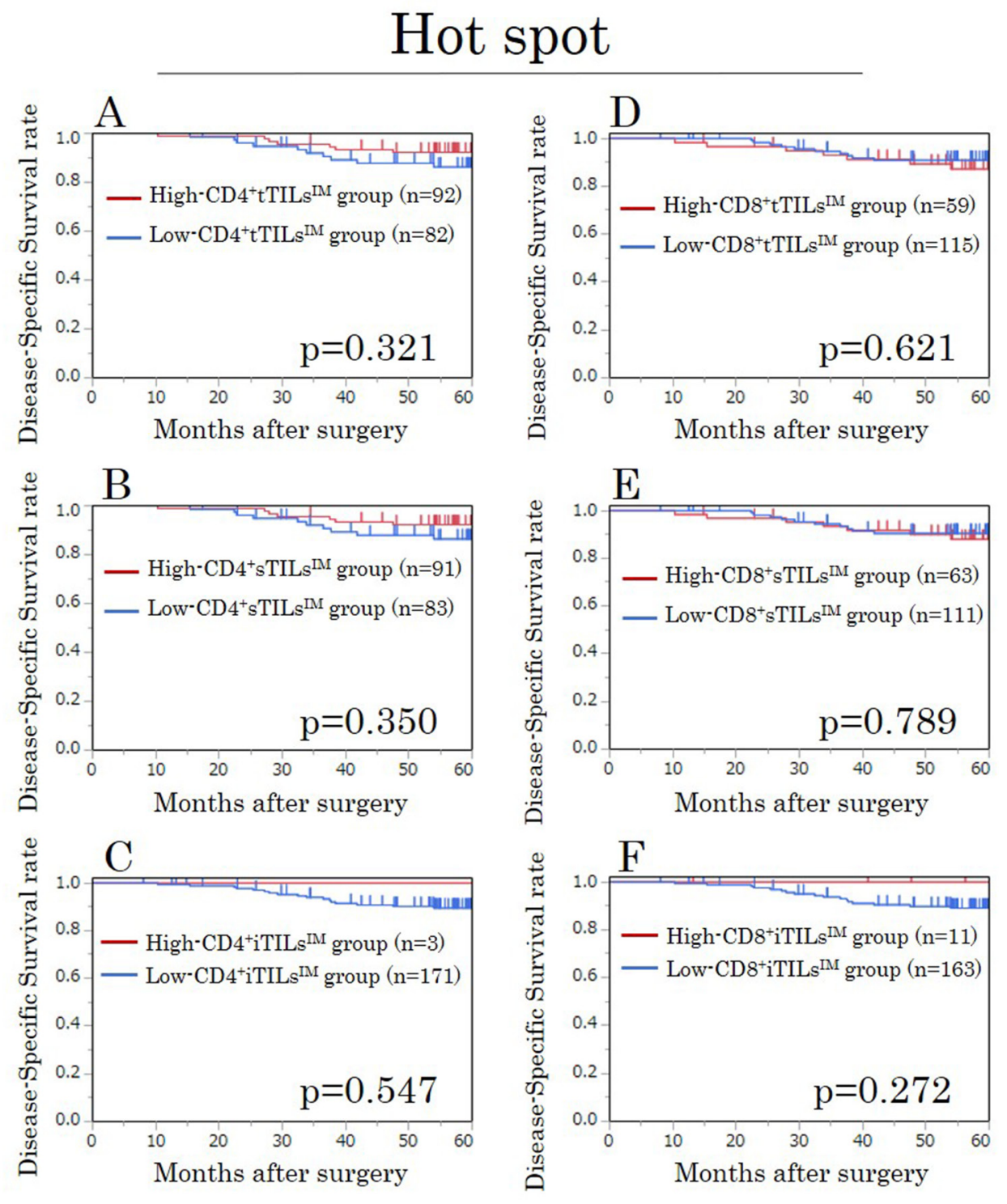

Figure 6: Kaplan-Meier survival curves for the disease-specific survival according to the density of CD4/CD8 ${ }^{+}$TILs at the invasive margin (TILs ${ }^{\mathrm{IM}}$ ) focusing on hot spots in the validation study. (A) CD4 ${ }^{+} \mathrm{tTILs}^{\mathrm{IM}}$. (B) CD $4^{+} \mathrm{sTILs}^{\mathrm{IM}}$. (C) CD $4^{+}{ }^{+} \mathrm{TILs}{ }^{\mathrm{IM}}$. (D) $\mathrm{CD}^{+} \mathrm{tTILs}^{\mathrm{IM}}$. (E) $\mathrm{CD}^{+} \mathrm{sTILs}^{\mathrm{IM}}$. (F) CD $8^{+}$iTILs $^{\mathrm{IM}}$. tTILs, total TILs. sTILs, TILs in tumor stroma. iTILs, TILs intra-tumor cells. 
Table 4: Correlations between the disease-specific survival and various clinicopathological factors in the validation study

\begin{tabular}{|c|c|c|c|c|c|c|}
\hline & \multicolumn{3}{|c|}{ Univariate analysis } & \multicolumn{3}{|c|}{ Multivariate analysis } \\
\hline & HR & $95 \% \mathrm{CI}$ & p-value & HR & $95 \% \mathrm{CI}$ & p-value \\
\hline Age $(\geq 65$ vs. $<65)$ & 0.916 & $0.361-2.491$ & 0.857 & 0.895 & $0.293-2.814$ & 0.845 \\
\hline Tumor depth (T4 vs. T1-3) & 1.813 & $0.692-4.599$ & 0.218 & 1.603 & $0.390-6.530$ & 0.505 \\
\hline $\begin{array}{l}\text { Histological type (Poorly, } \\
\text { Mucinous vs. Well, } \\
\text { Moderately) }\end{array}$ & 6.537 & $1.845-18.337$ & 0.006 & 1.557 & $0.384-5.528$ & 0.513 \\
\hline $\begin{array}{l}\text { Lymphatic involvement } \\
\text { (Positive vs. Negative) }\end{array}$ & 8.388 & $1.723-151.072$ & 0.004 & 3.765 & $0.652-71.445$ & 0.155 \\
\hline $\begin{array}{l}\text { Venous involvement (Positive } \\
\text { vs. Negative) }\end{array}$ & 1.872 & $0.652-4.823$ & 0.229 & 0.749 & $0.190-2.638$ & 0.660 \\
\hline $\begin{array}{l}\text { Lymph node metastasis } \\
\text { (Positive vs. Negative) }\end{array}$ & 7.053 & $2.326-30.449$ & $<0.001$ & 4.296 & $1.258-20.029$ & 0.019 \\
\hline CEA $(\geq 5 \mathrm{ng} / \mathrm{ml}$ vs. $<5 \mathrm{ng} / \mathrm{ml})$ & 2.636 & $1.037-7.167$ & 0.042 & 2.765 & $0.955-8.731$ & 0.061 \\
\hline $\begin{array}{l}\text { CA19-9 }(\geq 37 \mathrm{U} / \mathrm{ml} \text { vs. } \\
<37 \mathrm{U} / \mathrm{ml})\end{array}$ & 1.523 & $0.240-5.401$ & 0.596 & 2.301 & $0.325-10.372$ & 0.355 \\
\hline $\begin{array}{l}\text { The density of } \mathrm{CD}^{+} \mathrm{tTILs}^{\mathrm{IM}} \text { in } \\
\text { randomly selected field (Low } \\
\text { vs. High) }\end{array}$ & 15.918 & $5.695-56.251$ & $<0.001$ & 14.943 & $4.647-60.017$ & $<0.001$ \\
\hline $\begin{array}{l}\text { Mismatch repair status } \\
\text { (deficient vs. proficient) }\end{array}$ & $<0.001$ & NA & 0.151 & $<0.001$ & $0.000-32.813$ & $>0.999$ \\
\hline
\end{tabular}

HR, hazard ratio; CI, confidence interval; CEA, carcinoembryonic antigen; CA19-9, carbohydrate antigen 19-9; tTILs ${ }^{\mathrm{IM}}$, total tumor-infiltrating lymphocytes at the invasive margin; NA, not available.
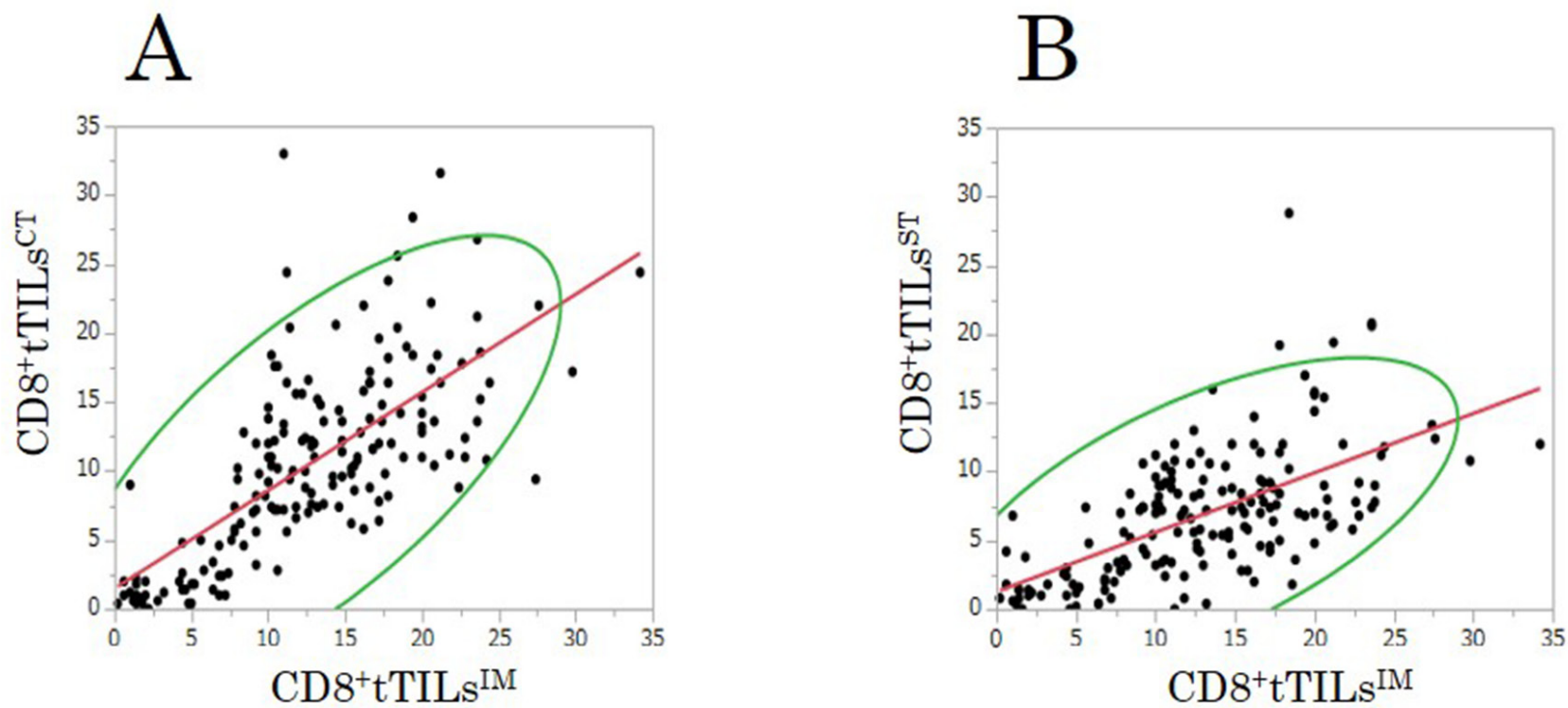

Figure 7: The correlations between the densities of total $\mathrm{CD8}^{+} \mathrm{TILs}$ at the center of the tumor $\left(\mathrm{CDB}^{+} \mathrm{tTILs}^{\mathrm{CT}}\right) / \mathrm{at}$ the surface of the tumor $\left(\mathrm{CD8}^{+} \mathrm{TTILs}^{\mathrm{ST}}\right)$ and that of total $\mathrm{CD8}^{+}$TILs at the invasive margin $\left(\mathrm{CDB}^{+} \mathrm{tTILs}^{\mathrm{IM}}\right)$ in randomly selected fields in the validation study. (A) center: $r=0.699$, $p<0.001$. (B) surface: $r=0.610, p<0.001$. 
In previous reports, when assessing the antitumor immunity, most researcher have evaluated the density of TILs at the invasive margin $[15,21]$ or the combination of the density of TILs at the invasive margin and those of TILs at the center of the tumor $[8,10,25]$. On the other hand, the density of TILs at the surface of the tumor in pretreatment biopsy samples of rectal cancer was recently

A

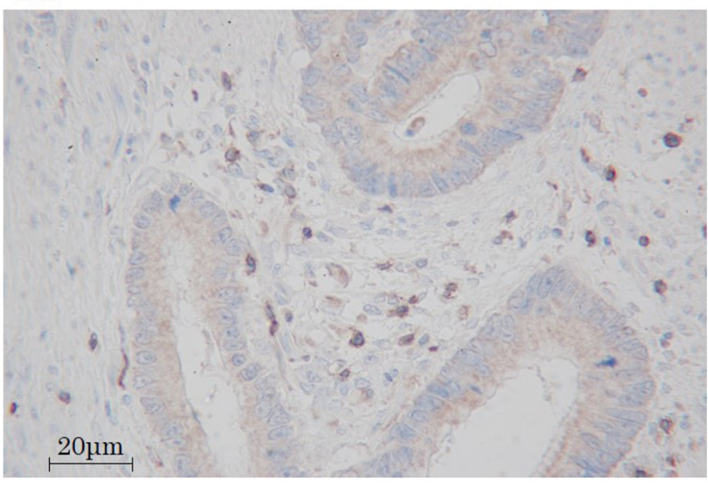

reported to be useful as a marker for predicting the response to neoadjuvant therapy in patients with locally advanced rectal cancer [29-31]. However, whether or not the density of TILs at the surface of the tumor accurately reflects the antitumor immune status of the whole tumor has been unclear. The current study showed that the density of TILs at the surface of the tumor was

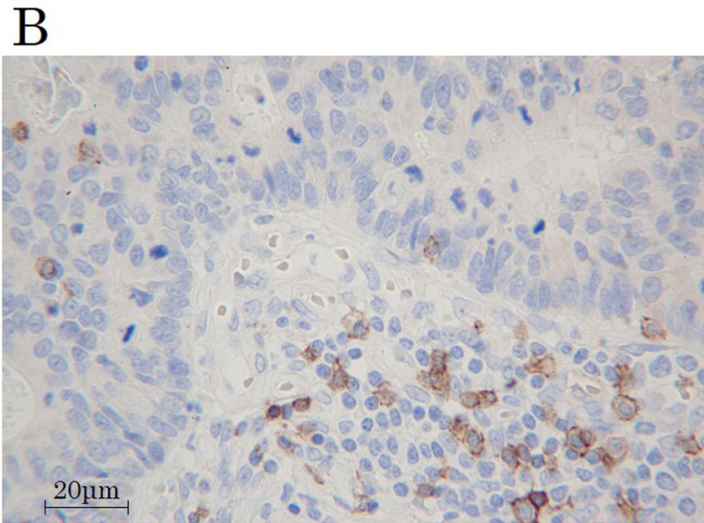

Figure 8: Immune marker expression of tumor-infiltrating lymphocytes. (A) CD4. (B) CD8. Magnification, 400×.

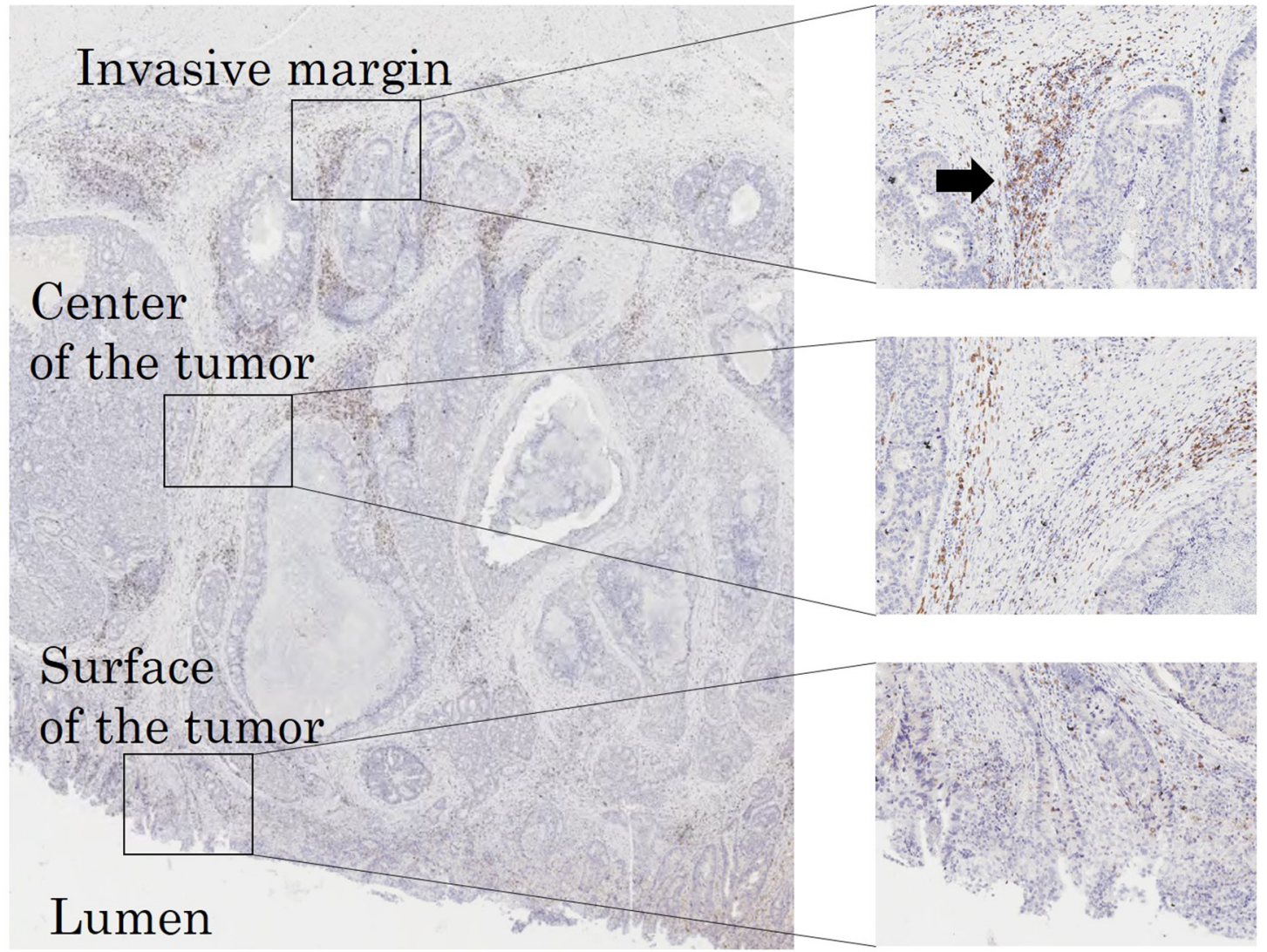

Figure 9: Immunoreactive TILs determined at each intratumoral subsite in low-power fields (invasive margin, the center of the tumor and the surface of the tumor). Hot spots are indicated by an arrow. 
Table 5: The number of TILs at the invasive margin (/field)

\begin{tabular}{lccccc}
\hline & \multicolumn{2}{c}{ Exploratory Group } & & \multicolumn{2}{c}{ Validation Group } \\
\cline { 2 - 3 } \cline { 5 - 6 } & At random & Hot spot & & At random & Hot spot \\
\hline CD4 (Median [range]) & & & & & \\
tTILs & $4.2(0-36.6)$ & $18.4(1.2-60.4)$ & & $2.2(0-13.8)$ & $18.8(4-51.0)$ \\
sTILs & $4.2(0-36.6)$ & $18.4(1.2-60.4)$ & & $2.2(0-13.8)$ & $18.8(4-51.0)$ \\
iTILs & $0(0-0.4)$ & $0(0-0.2)$ & & $0(0-2.2)$ & $0(0-4.4)$ \\
CD8 (Median [range]) & & & & \\
tTILs & $7.6(0.4-37.8)$ & $39(9.4-114.2)$ & & $12.5(0.2-34.2)$ & $32.6(7.0-79.6)$ \\
sTILs & $5.0(0-29.0)$ & $37.4(3.8-114.2)$ & & $11.6(0.2-29.8)$ & $32.6(7.0-79.6)$ \\
iTILs & $1.6(0-16.4)$ & $0(0-16.8)$ & & $0.2(0-12.8)$ & $0(0-4.0)$ \\
\hline
\end{tabular}

TILs: Tumor-infiltrating lymphocytes, tTILs: total TILs (sTILs+iTILs), sTILs: TILs in tumor stroma, iTILs: TILs intra tumor cells.

significantly associated with that of TILs at the invasive margin. We therefore concluded that the density of TILs at the surface of the tumor may reflect the antitumor immune status to some extent and may be secondary biomarkers of the antitumor immune status. This notion supports the findings of previous reports regarding the utility of assessing the antitumor immune status by evaluating the density of TILs at the surface of the tumor in pretreatment biopsy samples of rectal cancer as a predictive marker for response to neoadjuvant therapy [29-31].
Several limitations associated with the present study warrant mention. First, the current study was retrospective with relatively few patients. Second, we did not evaluate the fine subsets of $\mathrm{CD}^{+}$TILs and $\mathrm{CD}^{+}$TILs. Future studies should investigate the significance of the fine subsets of $\mathrm{CD}^{+}$cells (i.e. Th1, Th2, Th17, Treg cells) and $\mathrm{CD}^{+}$cells (i.e. $\mathrm{CD}^{+}$memory $\mathrm{T}$ cells) in antitumor immunity. Third, the optimum methodology of evaluating the density of TILs has not been established. In the current study, we counted the absolute number of TILs in order to

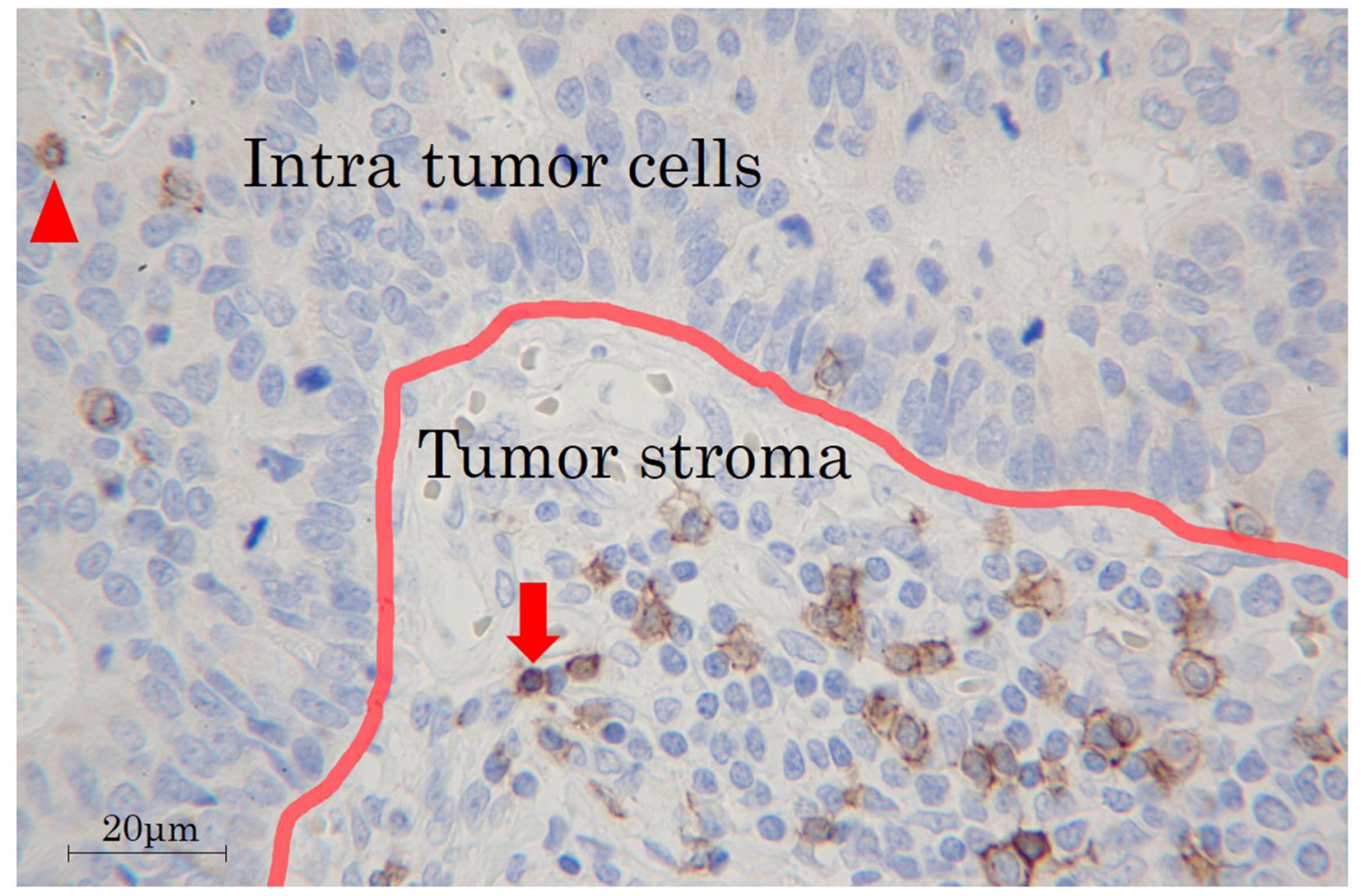

Figure 10: TILs in tumor stroma and intra-tumor cells. Arrowhead: iTILs, TILs intra-tumor cells. arrow: sTILs, TILs in tumor stroma. 

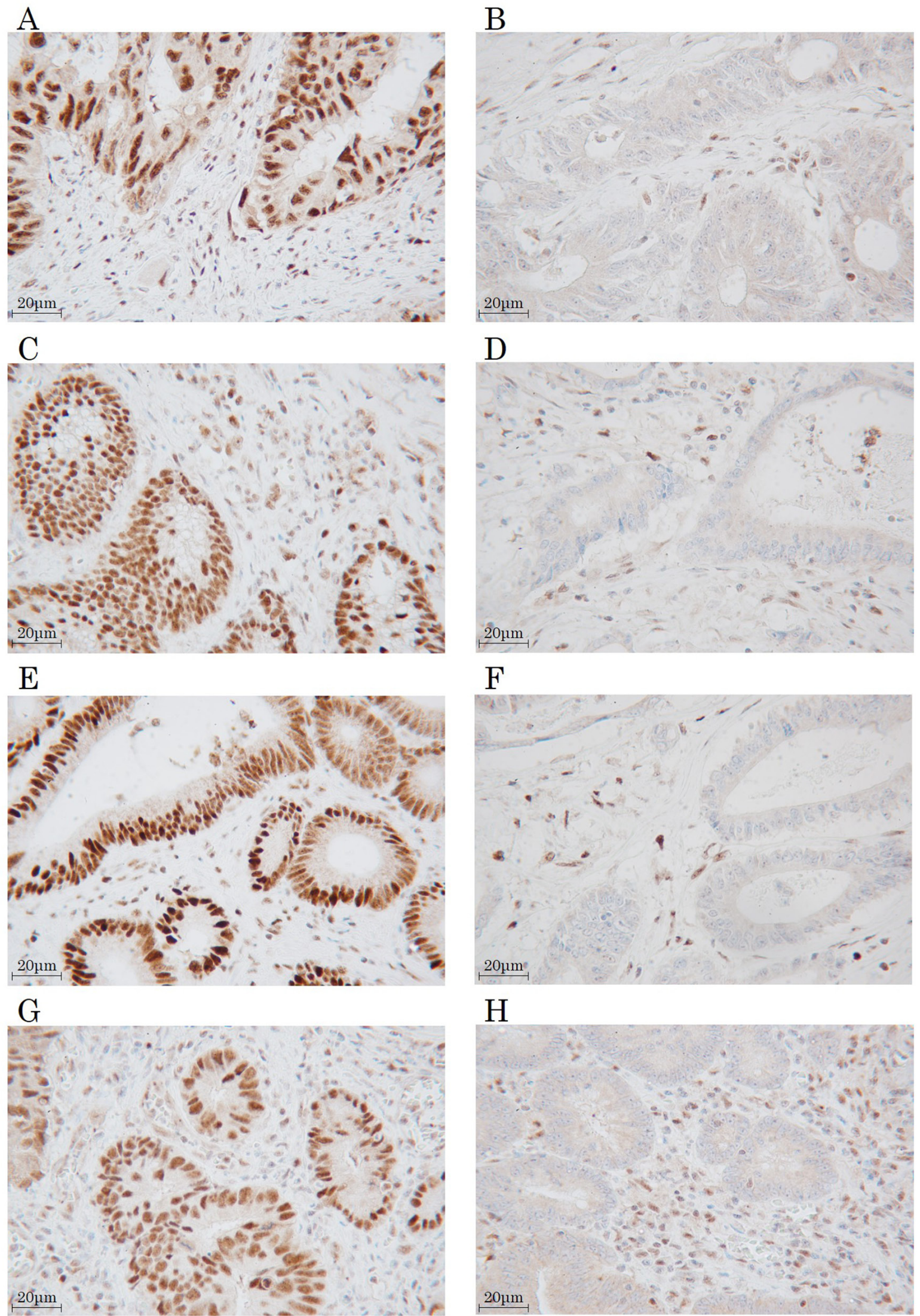

Figure 11: Immunohistochemical staining for mismatch repair proteins. MLH1 (A. positive, B. negative). MSH2 (C. positive, D. negative). MSH6 (E. positive, F. negative). PMS2 (G. positive, H. negative). Magnification, 400×. 
evaluate the antitumor immune status. However, Salgado et al. [32] evaluated the percentage of the area occupied by TILs in the tumor stroma area as a semiquantitative parameter (every 10\%), and Richards et al. [23] evaluated the density of TILs semi-quantitatively as absent, weak, moderate, or strong. Applying the evaluation of TILs in the clinical setting will require determining the optimum methodology of measuring the density of TILs. Fourth, in the current study we evaluated the average number of TILs in five different randomly selected fields in the tumor in order to resolve the issue of the heterogeneity of TILs. However, this issue still remains, making it necessary to establish a better method of evaluating the antitumor immune status for the whole tumor.

\section{CONCLUSIONS}

We concluded that the best and easiest way to evaluate the density of TILs in the clinical setting may be to assess the density of total CD8 ${ }^{+}$TILs at the invasive margin in randomly selected fields.

\section{PATIENTS AND METHODS}

\section{Patients}

A total of 313 patients with stage II/III CRC were enrolled in this study. All patients underwent potentially curative surgery for CRC at the Department of Surgical Oncology of Osaka City University between 2007 and 2012. Patients who received preoperative therapy, underwent emergency surgery for perforation/obstruction, or who had inflammatory bowel disease were excluded from this study.

All patients were divided into two groups: including the exploratory group, which consisted of 139 patients who underwent surgery between 2007 and 2009; and the validation group, which consisted of 174 patients who underwent surgery between 2010 and 2012 .

\section{Immunohistochemistry for CD4/CD8}

Surgically resected specimens were retrieved in order to perform the immunohistochemistry. All 4- $\mu$ mthick sections were deparaffined and rehydrated and then subjected to endogenous peroxidase blocking in $1 \% \mathrm{H}_{2} \mathrm{O}_{2}$ solution in methanol for 15 minutes. Antigen retrieval was performed by autoclaving the sections at $105^{\circ} \mathrm{C}$ for 10 minutes in Dako Target Retrieval Solution (Dako, Glostrup, Denmark). Serum blocking was performed with antibody $10 \%$ normal rabbit serum for 10 minutes. After $\mathrm{H}_{2} \mathrm{O}_{2}$ and serum blocking, the slides were incubated with primary mouse monoclonal anti-CD4 antibody (1:80 dilution; Dako) at room temperature for 20 minutes, and the slides were incubated with primary mouse monoclonal anti-CD8 antibody (1:100 dilution; Dako) at room temperature for 30 minutes. The secondary antibody was biotin-labeled rabbit anti-mouse $\operatorname{IgG}, \operatorname{IgA}, \operatorname{IgM}(1: 500$; Nichirei, Tokyo, Japan). Detection was performed with a DAB kit (Histofine simple stain kit; Nichirei). The sections were counterstained with hematoxylin.

The immunohistochemical evaluation was carried out by two independent pathologists who were blinded to the clinical information. We examined the average number of TILs in 5 different fields with a light microscope at $400 \times$ magnification by the following: 1) subsets of lymphocytes (i.e. $\mathrm{CD}^{+}$(Figure $8 \mathrm{~A}$ ) or $\mathrm{CD}^{+}$(Figure $8 \mathrm{~B}$ )), 2) selected fields (i.e. at random or focusing on hot spots (Figure 9)), 3) location in low-power field (Figure 9) (i.e. the invasive margin [TILs ${ }^{\mathrm{IM}}$ ] or the center of the tumor $\left[\mathrm{TILs}^{\mathrm{CT}}\right]$ or the surface of the tumor $\left.\left[\mathrm{TILs}^{\mathrm{ST}}\right]\right)$, 4) location in high-power field (Figure 10) (i.e. in tumor stroma [sTILs] or intra-tumor cells [iTILs] or total TILs [tTILs: sTILs+iTILs]). We set each median value as the cut-off value for the density of TILs evaluated by each method in the exploratory study (Table 5). In the validation study, we also used the cut-off value used in the exploratory study. We then classified the patients into the high- and low-TILs groups.

\section{Tissue microarray construction}

We constructed a tissue microarray (TMA) in order to evaluate the mismatch repair (MMR) status by immunohistochemical staining. A tissue microarray with one $3.0-\mathrm{mm}$-diameter punch core per cancer was constructed from formalin-fixed paraffin-embedded tissue blocks of all patients, as previously reported [33]. We ensured that the specific tumor histological type was representatively included in the TMA using HematoxylinEosin-stained TMA sections.

\section{Immunohistochemistry for mismatch repair status}

The effectiveness of an immunohistochemical analysis of the MMR proteins is reportedly similar to that of genotyping for microsatellite instability (MSI) [34]. Therefore, the MSI status was estimated based on the mismatch repair (MMR) status, as previously reported [35]. The MMR status was identified by immunohistochemical staining of MMR proteins (i.e. MLH1, MSH2, MSH6 and PMS2), as previously reported [36].

All 4- $\mu$ m-thick TMA slides were deparaffined and rehydrated and then subjected to endogenous peroxidase blocking in $1 \% \mathrm{H}_{2} \mathrm{O}_{2}$ solution in methanol for 15 minutes. Antigen retrieval was performed by autoclaving the sections at $121^{\circ} \mathrm{C}$ for 15 minutes in Dako Target Retrieval Solution (Dako). Serum blocking was performed with antibody $10 \%$ normal rabbit serum for 10 minutes. After $\mathrm{H}_{2} \mathrm{O}_{2}$ and serum blocking, the slides were incubated in 
primary antibody for 20 minutes for MLH1 (prediluted product), 20 minutes at a concentration of 1:50 for $\mathrm{MSH} 2$ and MSH6, and 30 minutes at a concentration of 1:40 for PMS2 at room temperature (product codes: IS079, M3639, M3646, M3647 [all from Dako]). The secondary antibody was biotin-labeled rabbit anti-mouse $\operatorname{IgG}, \operatorname{IgA}, \operatorname{IgM}$ (1:500; Nichirei). Detection was performed with a DAB kit (Histofine simple stain kit; Nichirei). The sections were counterstained with hematoxylin.

The MMR protein expression was evaluated by two pathologists blinded to the clinical outcomes. Normal colon tissue was used as a positive control, and positive staining within intra-tumoral immune cells was used as an internal positive control. The expression was evaluated as MMR-proficient (MMR-P) (tumor cell nuclear expression with positive immune cell expression) (Figure 11A, 11C, 11E, 11G) or MMR-deficient (MMR-D) (absent tumor cell nuclear expression with positive immune cell expression) (Figure 11B, 11D, 11F, 11H). One core was examined per patient for each MMR protein. The tumor was defined as MMR-D when one or more MMR proteins was negatively expressed.

\section{Statistical analyses}

The duration of the survival was calculated using the Kaplan-Meier method. Differences in the survival curves were assessed using the log-rank test. The significance of the correlations between TILs and the clinicopathological characteristics was analyzed using the $\chi^{2}$ test and Fisher's exact test. A multivariate analysis was performed according to the Cox proportional hazard model. Associations between the density of TILs ${ }^{\mathrm{IM}}$ and the density of TILs ${ }^{\mathrm{CT}} / \mathrm{TILs}^{\mathrm{ST}}$ was evaluated using the Pearson's correlation analysis. Associations between the density of TILs in MMR-P tumor and that in MMR-D tumor were analyzed using Wilcoxon's rank sum test. All of the statistical analyses were conducted using JMP ${ }^{\circledR}$ 13.0.0 software program (2016 SAS institute Inc., Cary, $\mathrm{NC}$, USA). P values of $<0.05$ were considered to indicate statistical significance.

\section{Ethical considerations}

This study conformed to the provisions of the Declaration of Helsinki. All patients were informed of the investigational nature of this study and provided their written informed consent. This retrospective study was approved by the ethics committee of Osaka City University (approved no. 3853).

\section{Abbreviations}

CA19-9-carbohydrate antigen 19-9; CEAcarcinoembryonic antigen; CI-confidence interval; CRCColorectal cancer; DSS-disease-specific survival; HR- hazard ratio; INF- $\gamma$-interferon- $\gamma$; iTILs-tumor-infiltrating lymphocytes intra-tumor cells; RFS-relapse-free survival; sTILs-tumor-infiltrating lymphocytes in tumor stroma; Th1 cells-T helper 1 cells; TILs-tumor-infiltrating lymphocytes; $\mathrm{TILs}^{\mathrm{CT}}$-tumor-infiltrating lymphocytes at the center of the tumor; TILs ${ }^{\mathrm{IM}}$-tumor-infiltrating lymphocytes at the invasive margin; TILs $^{\mathrm{ST}}$-tumor-infiltrating lymphocytes at the surface of the tumor; Treg cells-regulatory T cells; tTILs-total tumor-infiltrating lymphocytes

\section{Author contributions}

MS designed the study; SM and MS wrote the main manuscript text and prepared figures; SM did the experiments; SM, MS, KM, HN, TF and YI collected the samples. KM, KH and MO critically reviewed the manuscript. All authors read and approved the final manuscript.

\section{ACKNOWLEDGMENTS}

We thank Brian Quinn who provided medical writing services on behalf of JMC, Ltd. We also thank Associate Professor Kouji Yamamoto from the Department of Medical Statistics, Osaka City University Graduate School of Medicine.

\section{CONFLICTS OF INTEREST}

The authors confirm that there are no conflicts of interest in association with this study.

\section{FUNDING}

This research received no specific grants from any funding agency in the public, commercial or not-for-profit sectors.

\section{REFERENCES}

1. Howe HL, Wu X, Ries LA, Cokkinides V, Ahmed F, Jemal A, Miller B, Williams M, Ward E, Wingo PA, Ramirez A, Edwards BK. Annual report to the nation on the status of cancer, 1975-2003, featuring cancer among U.S. Hispanic/ Latino populations. Cancer. 2006; 107: 1711-42. https://doi. org/10.1002/cncr.22193.

2. Rudy DR, Zdon MJ. Update on colorectal cancer. Am Fam Physician. 2000; 61: 1759-70, 73-4.

3. McArdle CS, Hole DJ. Outcome following surgery for colorectal cancer: analysis by hospital after adjustment for case-mix and deprivation. Br J Cancer. 2002; 86: 331-5. https://doi.org/10.1038/sj.bjc.6600120.

4. Mlecnik B, Bindea G, Pages F, Galon J. Tumor immunosurveillance in human cancers. Cancer Metastasis Rev. 2011; 30: 5-12. https://doi.org/10.1007/s10555-011-9270-7. 
5. Locker GY, Hamilton S, Harris J, Jessup JM, Kemeny N, Macdonald JS, Somerfield MR, Hayes DF, Bast RC Jr. ASCO 2006 update of recommendations for the use of tumor markers in gastrointestinal cancer. J Clin Oncol. 2006; 24: 5313-27. https://doi.org/10.1200/ jco.2006.08.2644.

6. Angell H, Galon J. From the immune contexture to the Immunoscore: the role of prognostic and predictive immune markers in cancer. Curr Opin Immunol. 2013; 25: 261-7. https://doi.org/10.1016/j.coi.2013.03.004.

7. Fridman WH, Pages F, Sautes-Fridman C, Galon J. The immune contexture in human tumours: impact on clinical outcome. Nat Rev Cancer. 2012; 12: 298-306. https://doi. org/10.1038/nrc3245.

8. Galon J, Mlecnik B, Bindea G, Angell HK, Berger A, Lagorce C, Lugli A, Zlobec I, Hartmann A, Bifulco C, Nagtegaal ID, Palmqvist R, Masucci GV, et al. Towards the introduction of the 'Immunoscore' in the classification of malignant tumours. J Pathol. 2014; 232: 199-209. https:// doi.org/10.1002/path.4287.

9. Horne ZD, Jack R, Gray ZT, Siegfried JM, Wilson DO, Yousem SA, Nason KS, Landreneau RJ, Luketich JD, Schuchert MJ. Increased levels of tumor-infiltrating lymphocytes are associated with improved recurrencefree survival in stage 1A non-small-cell lung cancer. J Surg Res. 2011; 171: 1-5. https://doi.org/10.1016/j. jss.2011.03.068.

10. Pages F, Kirilovsky A, Mlecnik B, Asslaber M, Tosolini M, Bindea G, Lagorce C, Wind P, Marliot F, Bruneval P, Zatloukal K, Trajanoski Z, Berger A, et al. In situ cytotoxic and memory $\mathrm{T}$ cells predict outcome in patients with earlystage colorectal cancer. J Clin Oncol. 2009; 27: 5944-51. https://doi.org/10.1200/jco.2008.19.6147.

11. Pelletier MP, Edwardes MD, Michel RP, Halwani F, Morin JE. Prognostic markers in resectable non-small cell lung cancer: a multivariate analysis. Can J Surg. 2001; 44: 180-8.

12. Schumacher K, Haensch W, Roefzaad C, Schlag PM. Prognostic significance of activated $\mathrm{CD} 8(+) \mathrm{T}$ cell infiltrations within esophageal carcinomas. Cancer Res. 2001; 61: 3932-6.

13. Wahlin BE, Sander B, Christensson B, Kimby E. CD8+ T-cell content in diagnostic lymph nodes measured by flow cytometry is a predictor of survival in follicular lymphoma. Clin Cancer Res. 2007; 13: 388-97. https://doi. org/10.1158/1078-0432.ccr-06-1734.

14. Galon J, Pages F, Marincola FM, Thurin M, Trinchieri G, Fox BA, Gajewski TF, Ascierto PA. The immune score as a new possible approach for the classification of cancer. J Transl Med. 2012; 10: 1. https://doi.org/10.1186/1479-5876-10-1.

15. Kim Y, Bae JM, Li G, Cho NY, Kang GH. Image analyzerbased assessment of tumor-infiltrating $\mathrm{T}$ cell subsets and their prognostic values in colorectal carcinomas. PLoS One. 2015; 10: e0122183. https://doi.org/10.1371/journal. pone. 0122183 .
16. Nguyen N, Bellile E, Thomas D, McHugh J, Rozek L, Virani S, Peterson L, Carey TE, Walline H, Moyer J, Spector M, Perim D, Prince M, et al, and Head and Neck SPORE Program Investigators. Tumor infiltrating lymphocytes and survival in patients with head and neck squamous cell carcinoma. Head Neck. 2016; 38: 1074-84. https://doi.org/10.1002/hed.24406.

17. Noble F, Mellows T, McCormick Matthews LH, Bateman AC, Harris S, Underwood TJ, Byrne JP, Bailey IS, Sharland DM, Kelly JJ, Primrose JN, Sahota SS, Bateman AR, et al. Tumour infiltrating lymphocytes correlate with improved survival in patients with oesophageal adenocarcinoma. Cancer Immunol Immunother. 2016; 65: 651-62. https:// doi.org/10.1007/s00262-016-1826-5.

18. Xie Y, Akpinarli A, Maris C, Hipkiss EL, Lane M, Kwon EK, Muranski P, Restifo NP, Antony PA. Naive tumorspecific CD4(+) T cells differentiated in vivo eradicate established melanoma. J Exp Med. 2010; 207: 651-67. https://doi.org/10.1084/jem.20091921.

19. Galon J, Angell HK, Bedognetti D, Marincola FM. The continuum of cancer immunosurveillance: prognostic, predictive, and mechanistic signatures. Immunity. 2013; 39: 11-26. https://doi.org/10.1016/j.immuni.2013.07.008.

20. Obeid JM, Wages NA, Hu Y, Deacon DH, Slingluff CL Jr. Heterogeneity of CD8+ tumor-infiltrating lymphocytes in non-small-cell lung cancer: impact on patient prognostic assessments and comparison of quantification by different sampling strategies. Cancer Immunol Immunother. 2017; 66: 33-43. https://doi.org/10.1007/s00262-016-1908-4.

21. Mahmoud SM, Paish EC, Powe DG, Macmillan RD, Grainge MJ, Lee AH, Ellis IO, Green AR. Tumorinfiltrating $\mathrm{CD} 8+$ lymphocytes predict clinical outcome in breast cancer. J Clin Oncol. 2011; 29: 1949-55. https://doi. org/10.1200/jco.2010.30.5037.

22. Ling A, Edin S, Wikberg ML, Oberg A, Palmqvist R. The intratumoural subsite and relation of CD8(+) and FOXP3(+) $\mathrm{T}$ lymphocytes in colorectal cancer provide important prognostic clues. Br J Cancer. 2014; 110: 2551-9. https:// doi.org/10.1038/bjc.2014.161.

23. Richards $\mathrm{CH}$, Roxburgh $\mathrm{CS}$, Powell AG, Foulis AK, Horgan PG, McMillan DC. The clinical utility of the local inflammatory response in colorectal cancer. Eur J Cancer. 2014; 50: 309-19. https://doi.org/10.1016/j.ejca.2013.09.008.

24. Galon J, Pages F, Marincola FM, Angell HK, Thurin M, Lugli A, Zlobec I, Berger A, Bifulco C, Botti G, Tatangelo F, Britten CM, Kreiter S, et al. Cancer classification using the Immunoscore: a worldwide task force. J Transl Med. 2012; 10: 205. https://doi.org/10.1186/1479-5876-10-205.

25. Galon J, Costes A, Sanchez-Cabo F, Kirilovsky A, Mlecnik B, Lagorce-Pages C, Tosolini M, Camus M, Berger A, Wind P, Zinzindohoue F, Bruneval P, Cugnenc PH, et al. Type, density, and location of immune cells within human colorectal tumors predict clinical outcome. Science. 2006; 313: 1960-4. https://doi.org/10.1126/science.1129139. 
26. Ishikawa T, Fujita T, Suzuki Y, Okabe S, Yuasa Y, Iwai T, Kawakami Y. Tumor-specific immunological recognition of frameshift-mutated peptides in colon cancer with microsatellite instability. Cancer Res. 2003; 63: 5564-72.

27. Phillips SM, Banerjea A, Feakins R, Li SR, Bustin SA, Dorudi S. Tumour-infiltrating lymphocytes in colorectal cancer with microsatellite instability are activated and cytotoxic. Br J Surg. 2004; 91: 469-75. https://doi. org/10.1002/bjs.4472.

28. Gavin PG, Colangelo LH, Fumagalli D, Tanaka N, Remillard MY, Yothers G, Kim C, Taniyama Y, Kim SI, Choi HJ, Blackmon NL, Lipchik C, Petrelli NJ, et al. Mutation profiling and microsatellite instability in stage II and III colon cancer: an assessment of their prognostic and oxaliplatin predictive value. Clin Cancer Res. 2012; 18: 6531-41. https://doi.org/10.1158/1078-0432. ccr-12-0605.

29. Shinto E, Hase K, Hashiguchi Y, Sekizawa A, Ueno H, Shikina A, Kajiwara Y, Kobayashi H, Ishiguro M, Yamamoto J. CD8+ and FOXP3+ tumor-infiltrating T cells before and after chemoradiotherapy for rectal cancer. Ann Surg Oncol. 2014; 21: S414-21. https://doi.org/10.1245/ s10434-014-3584-y.

30. Teng F, Meng X, Kong L, Mu D, Zhu H, Liu S, Zhang J, Yu J. Tumor-infiltrating lymphocytes, forkhead box P3, programmed death ligand-1, and cytotoxic T lymphocyteassociated antigen-4 expressions before and after neoadjuvant chemoradiation in rectal cancer. Transl Res. 2015; 166: 72132.e1. https://doi.org/10.1016/j.trsl.2015.06.019.

31. Teng F, Mu D, Meng X, Kong L, Zhu H, Liu S, Zhang J, Yu J. Tumor infiltrating lymphocytes (TILs) before and after neoadjuvant chemoradiotherapy and its clinical utility for rectal cancer. Am J Cancer Res. 2015; 5: 2064-74.

32. Salgado R, Denkert C, Demaria S, Sirtaine N, Klauschen F, Pruneri G, Wienert S, Van den Eynden G, Baehner FL, Penault-Llorca F, Perez EA, Thompson EA, Symmans WF, et al, and International TILs Working Group 2014. The evaluation of tumor-infiltrating lymphocytes (TILs) in breast cancer: recommendations by an International TILs Working Group 2014. Ann Oncol. 2015; 26: 259-71. https:// doi.org/10.1093/annonc/mdu450.

33. Milanes-Yearsley M, Hammond ME, Pajak TF, Cooper JS, Chang C, Griffin T, Nelson D, Laramore G, Pilepich M. Tissue micro-array: a cost and time-effective method for correlative studies by regional and national cancer study groups. Mod Pathol. 2002; 15: 1366-73. https://doi. org/10.1097/01.mp.0000036345.18944.22.

34. Hampel H, Frankel WL, Martin E, Arnold M, Khanduja K, Kuebler P, Nakagawa H, Sotamaa K, Prior TW, Westman J, Panescu J, Fix D, Lockman J, et al. Screening for the Lynch syndrome (hereditary nonpolyposis colorectal cancer). N Engl J Med. 2005; 352: 1851-60. https://doi.org/10.1056/ NEJMoa043146.

35. Dudley JC, Lin MT, Le DT, Eshleman JR. Microsatellite Instability as a Biomarker for PD-1 Blockade. Clin Cancer Res. 2016; 22: 813-20. https://doi.org/10.1158/1078-0432. ccr-15-1678.

36. Hu J, Yan WY, Xie L, Cheng L, Yang M, Li L, Shi J, Liu BR, Qian XP. Coexistence of MSI with KRAS mutation is associated with worse prognosis in colorectal cancer. Medicine (Baltimore). 2016; 95: e5649. https://doi. org/10.1097/md.0000000000005649. 